\title{
Opposing Actions of Hippocampus TNFa Receptors on Limbic Seizure Susceptibility
}

\author{
Marc S. Weinberg, PhD'1, Bonita L. Blake, DVM, PhD², and Thomas J. McCown, PhD ${ }^{1,2}$ \\ ${ }^{1}$ Gene Therapy Center, University of North Carolina at Chapel Hill, Chapel Hill, NC \\ ${ }^{2}$ Department of Psychiatry, University of North Carolina at Chapel Hill, Chapel Hill, NC
}

\section{Abstract}

Resected epileptic tissues exhibit elements of chronic neuroinflammation that include elevated $\mathrm{TNFa}$ and increased TNFa receptor activation, but the seizure related consequences of chronic TNFa expression remain unknown. Twenty four hours after acute limbic seizures the rat hippocampus exhibited a rapid upregulation of TNFR1, but a simultaneous downregulation of TNFR2. These limbic seizures also evoked significant increases in measures of neuroinflammation and caused significant neuronal cell death in both the hilus and CA3 of the hippocampus. In order to mimic a state of chronic TNFa exposure, adeno-associated viral vectors were packaged with a TNF receptor 1 (TNFR1) specific agonist, human TNFa, or a TNF receptor $1 / 2$ agonist, rat TNFa. Subsequently, chronic hippocampal overexpression of either TNFR ligand caused microglial activation and blood-brain barrier compromise, a pattern similar to limbic seizure-induced neuroinflammation. However, no evidence was found for neuronal cell death or spontaneous seizure activity. Thus, chronic, in vivo TNFa expression and the subsequent neuroinflammation alone did not cause cell death or elicit seizure activity. In contrast, chronic hippocampal activation of TNFR1 alone significantly increased limbic seizure sensitivity in both amygdala kainic acid and electrical amygdala kindling models, while chronic activation of both TNFR1 and TNFR2 significantly attenuated the amygdala kindling rate. With regard to endogenous TNFa, chronic hippocampal expression of a TNFa decoy receptor significantly reduced seizure-induced cell death in the hippocampus, but did not alter seizure susceptibility. These findings suggest that blockade of endogenous TNFa could attenuate seizure related neuropathology, while selective activation of TNFR2 could exert beneficial therapeutic effects on in vivo seizure sensitivity.

\section{Introduction}

Over the last decade, both clinical and basic research has directly linked neuroinflammatory events with epilepsy (Vezzani et al. , 2012). Clinically, tissues resected from refractory temporal lobe epileptics exhibit a number of neuroinflammatory changes, such as increased IL-1 $\beta$ levels (Ravizza et al. , 2008), upregulated TNF-a receptor 1 (TNFR1) signaling

\footnotetext{
(C) 2012 Elsevier Inc. All rights reserved.

Corresponding Author: Thomas J. McCown, PhD UNC Gene Therapy Center 7119 Thurston, CB 7352 University of North Carolina at Chapel Hill Chapel Hill, NC 27599 Phone: 919-966-3081 FAX: 919-966-0907 thomas_mccown@med.unc.edu.

Publisher's Disclaimer: This is a PDF file of an unedited manuscript that has been accepted for publication. As a service to our customers we are providing this early version of the manuscript. The manuscript will undergo copyediting, typesetting, and review of the resulting proof before it is published in its final citable form. Please note that during the production process errors may be discovered which could affect the content, and all legal disclaimers that apply to the journal pertain.

Conflict of Interest

The authors declare no competing financial interests in relation to the work described.
} 
pathways (Yamamoto et al., 2006), increased CCL2 protein concentrations (Choi et al., 2009, Wu et al. , 2008), increased CSF levels of IL-6 (Lehtimaki et al. , 2004) and activated astrocytes (Bordey and Sontheimer, 1998). Additional neuropathological consequences include the presence of a compromised blood-brain barrier (BBB) and activated microglia (Hufnagel et al. , 2003). Although these chronic neuropathologies inevitably contribute to temporal lobe seizures, studies also have established direct in vivo seizure interactions for a wide range of neuroimmune modulators from TNF- $\alpha$ and IL1- $\beta$ to toll-like receptor- 4 and high mobility group box-1 (Dedeurwaerdere et al. , 2012).

A substantial literature suggests a direct role for TNF-a in seizure sensitivity, primarily from basic research studies that utilized acute manipulation of TNF-a function or transgenic mouse models. Balosso et al. (2005) found that acute, selective activation of TNFR1 by human TNF-a exerted no influence on hippocampal seizure sensitivity, but activation of both TNFR1 and TNFR2 by mouse TNF-a strongly inhibited seizure activity. Similarly, mice deficient in TNFR2 or both TNFR2 and TNFR1 exhibited increased seizure sensitivity, while astrocyte overexpression of TNF-a attenuated seizure sensitivity (Balosso et al. , 2005). From these findings the authors concluded that activation of TNFR2 attenuates seizure activity, while activation of TNFR1 did not influence seizure sensitivity. In contrast, Probert et al (1995) reported that neuronal overexpression of TNF- $a$ caused seizures and premature death. Clearly, these studies provided substantial insight into TNF-a interactions with seizures, but acute TNF-a manipulations do not faithfully recapitulate the clinical finding of chronic TNFa exposure. Furthermore, with transgenic animal models the results may be influenced by the likely developmental adaptation.

Adeno-associated virus (AAV) vectors provide the opportunity to mimic the chronic state of elevated TNF-a in vivo and determine the influence of this chronic activation on in vivo seizures. AAV vectors can non-toxically transduce cells in the CNS, and in most cases the transduction is predominantly neuronal (McCown, 2010). Since AAV vectors alone do not evoke significant neuroinflammation, gene expression would take place in the absence of any vector influence on neuroimmune function (Gorbatyuk et al. , 2008, Wang et al. , 2010). Thus, chronic vector-mediated TNF-a expression in the hippocampus should more closely mimic conditions found in tissue resected from intractable temporal lobe epileptics. The following studies characterized the influence of chronic TNF-a exposure, as well as the interactions between seizures and TNFR1 or TNFR2. The results demonstrate clear, opposing receptor-dependent actions of chronic TNF-a, and provide future directions for treating the pathology associated with temporal lobe epilepsy.

\section{Materials and Methods}

\section{Animals}

The animals were male Sprague-Dawley rats (Charles River, Morrisville, NC, USA) weighing between 275-300 grams. The rats were maintained in a 12-h light-dark cycle and had free access to water and food. All care and procedures were in accordance with the National Institutes of Health Guide for the Care and Use of Laboratory Animals and received prior approval by the University of North Carolina Institutional Animal Care and Usage Committee.

\section{Amygdala kainic acid delivery and time course tissue collection}

For intracranial kainic acid infusions, rats were anesthetized with isofluorane and placed into a stereotaxic frame. Using a 32-gauge stainless steel injector and a Fisher Scientific infusion pump, rats received $0.5 \mu \mathrm{l}$ of $1 \mu \mathrm{g} / \mu \mathrm{L}$ kainic acid over 2.5 minutes (Cayman Chemical Co., Ann Arbor, MI, USA, in $0.9 \%$ saline) to the right amygdala (bregma $-2.7 \mathrm{~mm}$, lateral -4.5 
$\mathrm{mm}$, skull $-8.2 \mathrm{~mm}$ ). The injector was left in place for $2 \mathrm{~min}$ after each infusion to allow diffusion from the injector. Time course intervals started immediately upon completion of kainic acid delivery, and at specified times, animals received an overdose of pentobarbital $(100 \mathrm{mg} / \mathrm{kg}$ pentobarbital, intraperitoneally) and were decapitated. The brains were immersed briefly in ice cold $0.01 \mathrm{M}$ phosphate buffered saline, and the hippocampus was removed and flash frozen in dry-ice.

\section{Western blot}

For the western blots hippocampal tissue was homogenized in a buffer containing a Complete Protease Inhibitor cocktail (Roche Diagnostics, Indianapolis, IN), and equal amounts of proteins were electrophoresed on a 4-20\% NuPAGE (Invitrogen Life Technologies) Bis-Tris gel, followed by transfer onto a nitrocellulose membrane (iBlot, Invitrogen Life Technologies). Membranes were blocked with 5\% fat-free milk for $1 \mathrm{~h}$ at room temperature (RT), followed by overnight incubation at $4{ }^{\circ} \mathrm{C}$ in the following primary antibodies: TNFR1 (abcam ab19139, 1:1000), TNFR2 (Cell Signaling, Beverly, MA, \#3727, 1:1000), CD11b (AbD Serotec, Raleigh, NC, MCA275, 1:1000) or MHC-II (Abcam ab23990, 1:1000). After washing, the membrane was incubated with anti-mouse IgG (antirabbit IgG for TNFR1/2) conjugated to horseradish peroxidase. The results were visualized with chemiluminescent substrate (SuperSignal West Femto, Pierce, Rockford, IL). The films were scanned and densitometry analyzed using the gel analysis function of ImageJ (NIH, Bethesda, MD). Results were standardized to $\beta$-actin (Abcam ab8224, 1:5000) from the same membrane. Bands were observed at: TNFR1: $52 \mathrm{kDa}$, TNFR2: $75 \mathrm{kDa}, \mathrm{CD} 11 \mathrm{~b}: 95$ kDa, MHC-II: bands of 28-31 kDa, NeuN: 46 and $48 \mathrm{kDa}$.

\section{Immunohistochemistry and image capture}

For TNFR1/TNFR2 immunohistochemistry, brains post-fixed in 4\% paraformaldehyde were paraffin-embedded, and $10 \mu$ thick sections were taken through the dorsal hippocampus. The sections were baked for $60^{\circ} \mathrm{C}$ for 2 hours and cooled to RT. Antigen retrieval was performed in a decloaking chamber (Biocare Medical, Concord, CA) with target retrieval buffer (DAKO S1699, Carpinteria, CA). After cooling, endogenous peroxidase activity was quenched by treating the slides with $3 \% \mathrm{H}_{2} \mathrm{O}_{2}$ for $10 \mathrm{~min}$, then $0.05 \mathrm{M}$ Tris buffer $2 \times 2$ minutes. After rinsing, the slides were placed in blocking buffer (DAKO X0909) for $30 \mathrm{~min}$ at RT, followed by incubation overnight in primary antibody at $4^{\circ} \mathrm{C}$ (TNFR1: Abcam [Cambridge, MA] ab19139 [1:1000] or TNFR2: Abcam ab15563 (1:50) in antibody diluent [DAKO S0809]). Subsequently, slides were washed and incubated in a secondary antibody (biotinylated goat anti-rabbit, Jackson ImmunoResearch, West Grove, PA, 1:500) for 1 hour at RT and subsequently reacted with avidin-biotin (Vector Labs, Burlingame, CA) followed by a $3,3^{\prime}$-diaminobenzidine nickel ammonium sulfate solution. Images were captured using a Nikon Microphot SA with a 2x objective, Nikon DXM 1200 color camera (Nikon, Melville, NY, USA), and ACT-1 software.

All other immunohistochemistry and image capture was performed as previously described (Weinberg et al., 2011), for the following antigens: NeuN (Chemicon, Temecula, CA, 1:1000), GFP (Millipore, Bedford, MA, 1:1000), rat IgG (Vector Laboratories, Burlingame, CA, 1:250), CD11b (AbD Serotec, Raleigh, NC, MCA275, 1:1000), and MHC-II (Abcam ab23990, 1:1000). Densitometric analysis of IgG extravasation was performed using ImageJ software (NIH, Bethesda, MD) with a reverse 0-255 scale. Relative densitometry was calculated based on the densitometry relative to the GFP-treated group average. Stereological analysis was performed identically as described previously (Weinberg et al., 2011), using Stereologer software (Stereology Resource Center, Inc., Chester, MD, USA). 


\section{TNFa, and TNFR:Fc subcloning and functional validation}

Plasmids containing the coding sequences for rat TNFa (rTNFa, NCBI accession BC107671) and human TNFa (hTNFa, NCBI accession NM_000594) were purchased from Open Biosystems (Thermo Scientific, Clone IDs 7938033, LIFESEQ95109283, respectively). Coding sequences were PCR amplified (Phusion DNA polymerase, New England Biolabs, Ipswich, MA) using oligomers (Integrated DNA Technologies, Coralville, Iowa) with AgeI-forward and Not1-reverse overhangs incorporated. Amplicons were digested with AgeI and NotI restriction enzymes (New England Biolabs) and ligated into pTR2/CBA-GFP, acquired from the UNC Gene Therapy Center Vector Core. TNFR1:Fc is a fusion protein composed of the extracellular domain of human type-I TNF receptor fused to the Fc (fragment crystallizable) region of a mouse IgG1 immunoglobulin molecule. TNFR1:Fc was PCR amplified from the plasmid pTNFR1:Fc (a kind gift of Dr. Jay K. Kolls, University of Pittsburgh School of Medicine to the UNC Gene Therapy Center), using AgeI/NotI primers and ligated into pTR2/CBA identically to the TNFa constructs. rTNFR2:Fc is a fusion protein composed of the extracellular domain of rat type-2 TNF receptor fused to the same Fc region as TNFR1:Fc. Rat TNFR2 extracellular domain (nucleotides 70-843 of NCBI NM_130426.4; OriGene, Rockville, MD) was fused to the mouse Fc region of TNFR1:Fc using nested PCR reactions. The PCR product then was ligated into PTR2/CBA. All sequences were verified by the UNC sequencing facility, or Eton Biosciences (Raleigh, NC).

\section{Functional validation of TNFa and TNFR:Fc constructs}

pTR/CBA-GFP, -rTNFa, and -hTNFa and pCMV-rTNFR2 plasmids were PEI-transfected into $10 \mathrm{~cm}$ cultures of Hela cells. Forty eight hours later, conditioned media was spun at 2500xG for $5 \mathrm{~min}$ at $4^{\circ} \mathrm{C}$ to clear cells and debris. Combinations of r/hTNFa and GFPconditioned media was incubated with rTNFR2:Fc- or GFP-conditioned media at $4^{\circ} \mathrm{C}$ for 30 min and subsequently replaced the media of a 24-well plate of Hela cells transfected $24 \mathrm{~h}$ prior with $\mathrm{p} 3 \mathrm{X}-\mathrm{\kappa B}-\mathrm{Luc}$ (firefly luciferase, a kind gift of Dr. Albert Baldwin, UNC Chapel Hill). Six hours after media transfer, the media was removed and replaced with $100 \mu \mathrm{L}$ of Passive Lysis buffer (Promega, Madison, WI). Cells were lysed for $10 \mathrm{~min}$ at RT and stored at $-20^{\circ} \mathrm{C}$ until luciferase assay. For luciferase assay, $100 \mu \mathrm{L}$ of Luciferin (Promega) was added to $10 \mathrm{uL}$ of cell lysis, and read on a Wallac1420 Victor2 automated plate reader. Results were reported relative to GFP/GFP conditioned media-treated p3X-кB-Luctransfected cells.

To test the functionality of TNFR1:Fc, HEK-293 cells conditioned to RPMI 1640 media (10\% FBS, $1 \%$ pen/strep) were transfected with pTR2/CBA-rTNFa, pTR/CBA-hTNFa, pTR/CBA-GFP, or pTR-CBA-TNFR1:Fc plasmids. Media was replaced at $24 \mathrm{~h}$. WEHI-164 clone 13 cells (a cell line highly sensitive to TNFa-induced apoptosis in absence of protein synthesis, obtained from the University of North Carolina Tissue Culture Facility) were plated at 2.5E4 cells in $100 \mu \mathrm{L}$ RPMI 1640 (10\% FBS, $1 \%$ pen/strep) on a 96-well plate and incubated $16 \mathrm{~h}$. Media was replaced with $50 \mu \mathrm{L}$ transfected HEK-293 media ( $48 \mathrm{~h}$ posttransfection) conditioned from GFP- or TNFR1:Fc-transfected cells, mixed with $8 \mu \mathrm{g} / \mathrm{mL}$ Actinomycin D (Sigma Aldrich, St. Louis, MO). An additional $50 \mu \mathrm{L}$ of HEK-293 media conditioned from GFP, rTNFa, or hTNFa transfection was applied undiluted, or diluted to $10 \%, 1 \%$, and $0.1 \%$ concentration in fresh RPMI 1640 media (10\% FBS, $1 \%$ pen/strep). Thus, the final concentrations of conditioned media (GFP, rTNFa, hTNFa) ranged from $50 \%-0.05 \%$, whereas the concentration of the soluble receptor media TNFR1:Fc (and control GFP media) was held constant at 50\% final concentration. Treatments were performed in triplicate. Twenty four hours after incubation at $37^{\circ} \mathrm{C}, 5 \% \mathrm{CO} 2$ in a humidified incubator, $20 \mathrm{uL}$ of MTS solution (Invitrogen, Grand Island, NY) was applied to each well, incubated for $1 \mathrm{~h}$, and absorbance determined, indicating relative viable cell number. Cell 
viability was determined relative to GFP/GFP-treated cells, which showed no evidence of the apoptotic shrinkage readily observed in $\mathrm{r} / \mathrm{hTNFa}$-treated cells.

\section{Recombinant virus production and quantification}

Recombinant AAV vectors were generated using HEK293 cells as described in Grieger and Samulski (2012). In brief, suspension HEK293 cells were transfected using a triple transfection method (Grieger et al., 2006), and 48 hours later, purified virus was obtained by loading the cell lysate onto a modified discontinuous iodixanol gradient. Purified virus was dialyzed against $1 \mathrm{X}$ phosphate-buffered saline (PBS) and 5\% sorbitol for 18 hours, and titers were calculated by qPCR according to established procedures (Grieger and Samulski, 2006).

\section{Intracranial AAV delivery, cannula and electrode placement}

Intracranial AAV infusions were performed in a manner similar to intracranial kainic acid delivery, with the following differences. In order to determine the effects of chronic TNF- $a$, rats received $3 \mu \mathrm{l}$ (2.4E9 vector genomes) AAV5/CBA-GFP -rTNF, -hTNF, or -TNFR:Fc unilaterally the right dorsal hippocampus (bregma $-4.2 \mathrm{~mm}$, lateral $-3.0 \mathrm{~mm}$, skull $-3.7 \mathrm{~mm}$ ). For the seizure studies, these AAV vectors were infused bilaterally. For amygdala-directed KA treatment, rats were implanted with a guide cannula (12 $\mathrm{mm}$ length, 26-gauge stainless steel implanted over the amygdala bregma $-2.7 \mathrm{~mm}$, lateral $-4.5 \mathrm{~mm}$, skull $-4.2 \mathrm{~mm}$ ). Cannulae were fixed with dental cement to three screws in the skull. After surgery an obturator was placed into the guide cannula extending $0.5 \mathrm{~mm}$ beyond the tip of the guide. Rats recovered for approximately 1 week prior to KA treatment. For amygdala-directed KA, a 32-gauge microinjector was placed into the cannula such that the tip terminated in the amygdala. KA $(0.5 \mathrm{mg} / \mathrm{ml})$ was administered in a total volume of $0.5 \mu$ Linfused over 2.5 $\mathrm{min}$. Subsequent video recordings were generated using Q-See monitoring (Anaheim, CA); analysis of seizure activity was based on the seizure motor scale of Racine (1972). For the electrical kindling studies, a waveform generator (World Precision Instruments) delivered a single 400 microamp bipolar stimulation ( $60 \mathrm{~Hz}, 1.7 \mathrm{~ms}$ pulse interval, pulse width $0.5 \mathrm{~ms}$, train duration $2 \mathrm{~s}$ ) using a constant current stimulus isolation unit. Rats were stimulated once daily, and the post-stimulus seizure duration was timed.

\section{Statistical Analysis}

One-way ANOVAs or student $t$-tests were used for all collected data, with Pearson's correlation analysis performed for a subset of western blot results. Fisher's Least Significant Differences test was used as a common Post-hoc test, when omnibus ANOVA p-values were $<0.05$.

\section{Results}

\section{Generalized Limbic Seizures Differentially Alter TNFRs and Evoke Immune Responses in the Hippocampus}

TNFR1-like immunoreactivity and TNFR2-like immunoreactivity were found in neuronal cell layers of the normal hippocampus, but 24 hours after limbic seizure activity was evoked by amygdala kainic acid infusion, the hippocampus exhibited an apparent increase in TNFR1-like immunoreactivity and an apparent decrease in TNFR2-like immunoreactivity (Figure $1 \mathrm{~A}, \mathrm{~B}$ ). These observations were validated by Western blot analysis (Figure 1 C, D) where hippocampal TNFR1 levels increased significantly as compared to controls, while TNFR2 levels decreased significantly. Although this generalized limbic seizure activity caused cell damage in the hippocampus 24h-post treatment (data not shown), early cell death could not be the sole source for these divergent changes in TNFR subtypes, given the strong negative correlation between hippocampal TNFR1 and TNFR2 protein levels across 
all time points (Fig. 1D, inset). The amygdala initiated limbic seizure activity also evoked a substantial immune response in the hippocampus. MHCII and CD11b levels were significantly increased at $8 \mathrm{~h}$ post-kainic acid (Figure $1 \mathrm{E}, \mathrm{F}, \mathrm{G}$ ).

\section{Effects of Rat or Human TNFa Expression on TNFRs}

Previous studies have shown that mouse TNF- $a$ activated both mouse TNFR1 and TNFR2 while human TNF-a (hTNF-a) only activated mouse TNFR1 (Lewis et al., 1991). Previously, Childs et al. (2001) showed that a TNFR1-mouse IgG fusion protein selectively bound TNF- $\alpha$ and prevented TNFR1 receptor activation. Therefore, we constructed a plasmid that expressed a TNFR2-mouse IgG fusion protein (TNFR2:Fc) in order to determine the specificity of rat and human TNF- $a$ on rat TNFRs (Figure 2 A). In the presence of GFP expression, both rTNF- $a$ and hTNF- $a$ significantly stimulated $\mathrm{kB}$-based gene expression in HeLa cells (Figure $2 \mathrm{~B}$ ). However, expression of rat TNFR2:Fc fully blocked rTNF- $a$-induced $\kappa B$-luc activity, but did not prevent hTNF- $a$-induced $\kappa B$-luc activity. These results confirmed that as in the mouse, hTNF-a did not bind rat TNFR2.

\section{Effects of Chronic TNFa Expression on TNFRs and Immune Responses in the Hippocampus}

Recombinant adeno-associated virus serotype 5 (rAAV5) vectors were packaged with the cassettes that expressed rTNF-a, hTNF-a or GFP. As previously shown (Burger et al., 2004, Weinberg et al. , 2011), the AAV5 vector supported neuronal GFP gene expression throughout the dorsal hippocampus, including hilar, CA1 and CA3 cell bodies. One week after the TNFa vectors were infused into the dorsal hippocampus, chronic rTNF-a expression caused a robust upregulation of MHC-II in the dorsal hippocampus, while hTNFa expression led to a more modest, but clear MHC-II upregulation (Figure 3 A). Similarly, chronic rTNF- $a$ or hTNF- $a$ expression increased CD11b immunostaining with rTNF- $a$ causing a more robust $\mathrm{CD} 11 \mathrm{~b}$ response than hTNF-a. Also, as previously demonstrated after acute TNF- $\alpha$ administration (Wright and Merchant, 1994), chronic rTNF- $\alpha$ or hTNF- $\alpha$ expression in the dorsal hippocampus led to significant $\operatorname{IgG}$ extravasation into the parenchyma distinct from any injection artifact (Figure $3 \mathrm{~A}, \mathrm{~B}$ ). In contrast to the results after limbic seizure activity, one week after hippocampal infusion of either AAV-rTNF- $a$ or AAV-hTNF- $a$ vectors, western blots showed a significant reduction in TNFR1 but no change in TNFR2 (Figure 4). Surprisingly, the presence of this elevated immune milieu and compromised blood-brain barrier did not cause neuronal cell death throughout any of the dorsal hippocampus after 1 week (Figure $3 \mathrm{~A}$ ), or as long as 7 weeks after vector delivery (data not shown).

\section{The Effects of Chronic TNFa Expression on In Vivo Seizure Sensitivity}

Although chronic hippocampal expression of rTNF-a or hTNF-a alone did not prove sufficient to cause cell death or elicit spontaneous limbic seizure activity (data not shown), subsequent studies identified significant interactions of chronic TNF- $a$ expression on seizure susceptibility. Initially, rTNF-a or hTNF-a vectors were injected bilaterally into the dorsal hippocampus, and one week later the rats received a $0.5 \mu \mathrm{L}$ infusion of kainic acid $(0.5 \mu \mathrm{g} / \mu \mathrm{L})$ into the amygdala. Chronic rTNF- $a$ expression in the hippocampus did not produce any difference in the number or duration of kainic acid-induced limbic seizure activity, but chronic hTNF-a expression caused a significant increase in the number of class IV seizures (Racine, 1972)(Figure 5 A). When limbic seizures were elicited by electrical kindling of the amygdala, prior chronic hippocampal expression of rTNF-a significantly increased the number of electrical stimulations necessary for rats to exhibit three sequential class IV seizures, while hippocampal hTNFa expression significantly reduced the number of kindling stimulations needed to elicit three sequential class IV seizures (Figure 5 B). Despite this reduced number of stimulations necessary to elicit class IV seizures, the average 
seizure duration was significantly longer in hTNF-a treated rats versus control rats or rTNFa treated rats (Figure $5 \mathrm{C}$ ).

\section{Influence of Endogenous TNF- $\alpha$ on Seizure-induced Cell Death and Seizure Sensitivity}

In order to determine the influence of endogenous TNF-a on seizure activity, we utilized a fusion TNFR1:Fc molecule. Initially, in vitro studies were conducted to verify the biological activity of AAV vector-derived TNFR1:Fc. We incubated GFP, rTNF- $a$, and hTNF-a containing conditioned media with either GFP or TNFR1:Fc containing medium, and applied the combined media to WEHI-164 clone 13 cells. rTNF-a or hTNF- $a$ conditioned media led to significant apoptosis in the WEHI-164 as compared to GFP-treated cells, but incubation of either rTNF- $a$ or hTNF- $a$ with TNFR1:Fc prevented TNF- $a$-induced apoptosis (Figure 6 A). Given this in vitro validation of biological activity, we infused AAV5-TNFR1:Fc vectors 1 week prior to amygdala kainic acid administration. TNFR1:Fc expression significantly reduced the seizure-induced cell death relative to AAV5-GFP (Figure 6 B). However, unilateral infusion of AAV5-TNFR1:Fc did not alter the seizure response to ipsilateral amygdala kainic acid, and bilateral hippocampal AAV5-TNFR1:Fc infusion did not alter the course of electrical amygdala kindling 1 week post-vector treatment either in the rate of kindling or seizure duration (Figure $6 \mathrm{C}$ ).

\section{Discussion}

Over the past decade conclusive evidence indicates that not only do seizures cause long-term neuroimmune consequences but that some immune factors can produce pro-convulsive actions (Balosso et al. , 2005, Crespel et al. , 2002, Ravizza et al. , 2008, Yamamoto et al. , 2006). Given the chronic elevation of TNF-a activity in resected temporal lobe epileptics (Yamamoto et al., 2006), we investigated the interplay of limbic seizures and hippocampal TNF- $a$ activity. Overall, the studies show that limbic seizures cause a pro-convulsant change in TNFRs, and chronic in vivo expression of TNF-a increases in vivo seizure sensitivity through TNFR1 activation. In contrast, blockade of endogenous TNF-a significantly attenuates seizure-induced cell death, while activation of TNFR2 exerts an antiseizure effect in vivo.

\section{Seizures and TNFR Expression Patterns in the Hippocampus}

When limbic seizures were elicited by amygdala kainic acid, subsequent seizure generalization into the hippocampus caused a significant increase in hippocampal TNFR1 with a concomitant decrease in hippocampal TNFR2. Previous studies by Balosso et al. (2005) found that transgenic TNFR1 deficient mice were less seizure-responsive to kainic acid, while mice lacking TNFR2 exhibit a greater kainic acid seizure susceptibility. Thus, the combination of increased TNFR1 with decreased TNFR2 should create a pro-convulsant state in the hippocampus. This pro-convulsant state, however, was not a result of chronic TNF- $a$ expression alone, because chronic rTNF- $a$ or hTNF- $a$ overexpression caused a decrease in hippocampal TNFR1 and no change in TNFR2. Given this divergence between seizures and AAV mediated chronic TNF-a exposure, seizure-induced changes in TNFRs inevitably involve additional, endogenous factors, such as the release of interleukin $1-\beta$ (Vezzani et al. , 2011).

\section{Chronic Activation of Hippocampal TNFRs}

Even though AAV vector mediated TNF- $a$ expression likely does not exactly recapitulate the chronic seizure milieu, observed changes do closely reflect the chronic inflammatory state seen in resected temporal lobe tissue. In naïve rats AAV mediated hTNF- $a$ or rTNF- $a$ overexpression caused significant microglial activation and increased blood-brain barrier (BBB) permeability. Surprisingly, this state of chronic inflammation and BBB compromise 
did not result in any overt cell death. Generally, TNFR1 activation initiates the recruitment of TNF receptor-associated death domain (TRADD), a Fas-associated death domain protein (FADD) and subsequent caspase 8 induced apoptosis. However, the TRADD also can recruit receptor-interacting protein 1 , which through interactions with TNFR associated factor 2 causes NF- $\mathrm{KB}$ activation, cellular proliferation and inflammation (Naude et al., 2011). Obviously, chronic expression of hTNF-a in neurons was not sufficient to activate TNFR1 mediated apoptosis. Similarly, substantial evidence has established that experimentally induced BBB breakdown can directly induce epileptic foci (Seiffert et al., 2004), but the significant compromise in BBB function induced by chronic TNF-a overexpression did not result in spontaneous seizure activity. Therefore, in the absence of additional insults BBB compromise alone did not prove sufficient to elicit seizure activity. However, this BBB compromise likely contributed to the in vivo seizure sensitivity, as previously demonstrated (Marchi et al. , 2007, van Vliet et al. , 2007). Finally, the vector mediated expression is almost entirely neuronal in nature, so these overall findings clearly contrast the phenotype of transgenic mice where neuronal overexpression of TNF-a resulted in seizures and early mortality (Probert et al., 1995).

\section{Chronic TNFR Activation Influences Seizure Sensitivity}

In two different limbic seizure models chronic expression of hTNF-a, a TNFR1-specific ligand, significantly increased seizure sensitivity. Significant increases were found both in the number of seizures after amygdala kainic acid administration and in the kindling rate and seizure duration in the electrical amygdala kindling model. Obviously, chronic, selective activation of TNFR1 increased in vivo seizure sensitivity, in contrast to acute TNFR1 activation which did not influence kainic acid-induced seizures (Balosso et al. , 2005). Certainly, resected tissue from patients with temporal lobe epilepsy have increased TNFR1 protein expression and increased TNFR1-signaling (Yamamoto et al. , 2006). Thus, the presence of elevated TNF-a would favor activation of TNFR1 leading to an increase in seizure sensitivity. In contrast, chronic activation of both TNFR1 and TNFR2 by rTNF-a overexpression significantly decreased the rate of amygdala kindling. As suggested previously (Balosso et al., 2005) activation of TNFR2 appears to exert an anti-seizure action in vivo, even with concomitant TNFR1 activation by chronic rTNF-a expression.

\section{Effects of Blocking Seizure-induced TNFa Activity in the Hippocampus}

By chronically expressing a potent decoy receptor for TNF-a, we were able to evaluate the role of endogenous TNF-a release on seizure-induced cell death and in vivo seizure sensitivity. Hippocampal-specific expression of the decoy TNF-a significantly suppressed seizure-induced cell death in both the hilus and CA3. This finding not only supports previous studies where TNF-a proved important for modulation of cell death in these neuronal populations (Shinoda et al. , 2003), but also validates the in vivo activity of the vector derived decoy TNF receptor. Previous studies have found that TNFR1 or TNFR1/R2 knockout mice actually exhibit an increased cell death in response to excitotoxic insult (Bruce et al. , 1996, Gary et al. , 1998). These contrasting results likely arise from differences between partial blockade of TNF-a function using soluble receptor-antibody chimeras versus unconditional loss of receptor activity over the course of development.

TNF-a blockade, however, did not alter seizure activity in either the kainic acid or amygdala kindling models. Both kainic acid-induced seizures and amygdala-kindled seizures increase the expression of TNF-a (Minami et al. , 1991; Plata-Salaman et al., 2000), which would be expected to activate both TNFR1 and TNFR2. Although attenuation of TNF- $a$ actions on TNFR1 would reduce the pro-seizure influence of TNFR1, simultaneous reduction of TNF- $a$ actions on TNFR2 would reduce the anti-seizure actions mediated through the TNFR2 receptor. Alternatively, the localized attenuation of TNF-a 
may not prove sufficient to alter the broad systems-level plasticity required for generalized limbic seizures. For example, Riazi (2008) reported a significant anti-seizure effect of effect of TNF-a neutralizing antibodies when the antibodies were administered intraventricularly.

\section{Conclusions}

Our findings show that after limbic seizures, hippocampal TNFR1 protein expression increases and TNFR 2 protein expression decreases, a change that should favor a proconvulsant state. In addition, chronic hippocampal TNFR1 activation induces an increased seizure propensity in two limbic seizure models. Chronic activation of TNFR1/2, however, exerts anti-seizure properties, even in the context of presumptive, simultaneous activation of TNFR1. With regard to endogenous TNF- $a$, vector mediated expression of a decoy TNFR1 prevented seizure-induced cell death, but did not alter in vivo seizure sensitivity. Thus, blockade of endogenous TNF-a should attenuate seizure-induced pathology, whereas attenuation of seizure activity will likely require selective activation of TNFR2.

\section{Acknowledgments}

The authors would like to thank Dr. Josh Grieger and Steve Soltys of the UNC Gene Therapy Center Vector Core for their advice regarding vector production and purification. We also thank Dr. Chengwen Li and Swati Yadav of the Samulski Lab (UNC), Kirk McNaughton of the UNC Cell and Molecular Physiology Histology Research Core Facility, and Michael Chua and Dr. Neal Kramarcy of the UNC Hooker Microscopy core facility for technical assistance.

Funding

This work was supported by the National Institutes of Health (NS035633 to T.J.M; F32NS070356 to M.S.W).

\section{Footnote Abbreviations}
TNF-a
tumor necrosis factor-alpha
TNFR
tumor necrosis factor receptor
AAV
adeno-associated virus

\section{References}

Balosso S, Ravizza T, Perego C, Peschon J, Campbell IL, De Simoni MG, Vezzani A. Tumor necrosis factor-alpha inhibits seizures in mice via p75 receptors. Ann. Neurology. 2005; 57:804-12.

Bordey A, Sontheimer H. Properties of human glial cells associated with epileptic seizure foci. Epilepsy Res. 1998; 32:286-303. [PubMed: 9761328]

Bruce AJ, Boling W, Kindy MS, Peschon J, Kraemer PJ, Carpenter MK, Holtsberg FW, Mattson MP. Altered neuronal and microglial responses to excitotoxic and ischemic brain injury in mice lacking TNF receptors. Nat. Med. 1996; 2:788-94. [PubMed: 8673925]

Burger C, Gorbatyuk OS, Velardo MJ, Peden CS, Williams P, Zolotukhin S, Reier PJ, Mandel RJ, Muzyczka N. Recombinant AAV viral vectors pseudotyped with viral capsids from serotypes 1, 2, and 5 display differential efficiency and cell tropism after delivery to different regions of the central nervous system. Mol. Ther. 2004; 10:302-17. [PubMed: 15294177]

Childs LM, Goater JJ, O'Keefe RJ, Schwarz EM. Effect of anti-tumor necrosis factor-alpha gene therapy on wear debris-induced osteolysis. J.Bone Joint Surg. AM. 2001; 83-A:1789-97. [PubMed: 11741056]

Choi J, Nordli DR Jr. Alden TD, DiPatri A Jr. Laux L, Kelley K, Rosenow J, Schuele SU, Rajaram V, Koh S. Cellular injury and neuroinflammation in children with chronic intractable epilepsy. J. Neuroinflam. 2009; 6:38. 
Crespel A, Coubes P, Rousset MC, Brana C, Rougier A, Rondouin G, Bockaert J, Baldy-Moulinier M, Lerner-Natoli M. Inflammatory reactions in human medial temporal lobe epilepsy with hippocampal sclerosis. Brain Res. 2002; 952:159-69. [PubMed: 12376176]

Dedeurwaerdere S, Friedman A, Fabene PF, Mazarati A, Murashima YL, Vezzani A, Baram TZ. Finding a better drug for epilepsy: Antiinflammatory targets. Epilepsia. 2012; 53:1113-8. [PubMed: 22691043]

Gary DS, Bruce-Keller AJ, Kindy MS, Mattson MP. Ischemic and excitotoxic brain injury is enhanced in mice lacking the p55 tumor necrosis factor receptor. Journal of cerebral blood flow and metabolism. J. Cereb. Blood Flow and Metab. 1998; 18:1283-7. [PubMed: 9850139]

Gorbatyuk OS, Li S, Sullivan LF, Chen W, Kondrikova G, Manfredsson FP, Mandel RJ, Muzyczka N. The phosphorylation state of Ser-129 in human alpha-synuclein determines neurodegeneration in a rat model of Parkinson disease. Proc. Nat. Acad. Sci. 2008; 105:763-8. [PubMed: 18178617]

Grieger JC, Choi VW, Samulski RJ. Production and characterization of adeno-associated viral vectors. Nat. Protocols. 2006; 1:1412-28.

Hufnagel A, Weber J, Marks S, Ludwig T, De Greiff A, Leonhardt G, Widmann G, Stolke D, Forsting M. Brain diffusion after single seizures. Epilepsia. 2003; 44:54-63. [PubMed: 12581230]

Lehtimaki KA, Keranen T, Huhtala H, Hurme M, Ollikainen J, Honkaniemi J, Palmio J, Peltola J. Regulation of IL-6 system in cerebrospinal fluid and serum compartments by seizures: the effect of seizure type and duration. J. Neuroimmunol. 2004; 152:121-5. [PubMed: 15223244]

Lewis M, Tartaglia LA, Lee A, Bennett GL, Rice GC, Wong GH, Chen EY, Goeddel DV. Cloning and expression of cDNAs for two distinct murine tumor necrosis factor receptors demonstrate one receptor is species specific. Proc. Nat. Acad. Sci. 1991; 88:2830-4. [PubMed: 1849278]

Marchi N, Angelov L, Masaryk T, Fazio V, Granata T, Hernandez N, Hallene K, Diglaw T, Franic L, Najm I, Janigro D. Seizure-promoting effect of blood-brain barrier disruption. Epilepsia. 2007; 48:732-42. 2007. [PubMed: 17319915]

McCown TJ. The future of epilepsy treatment: focus on adeno-associated virus vector gene therapy. Drug News \& Perspectives. 2010; 23:281-6. [PubMed: 20603651]

Minami M, Kuraishi Y, Satoh M. Effects of kainic acid on messenger RNA levels of IL-1 beta, IL-6, TNF alpha and LIF in the rat brain. Biochem. Biophy. Res. Comm. 1991; 176:593-8.

Naude PJ, den Boer JA, Luiten PG, Eisel UL. Tumor necrosis factor receptor cross-talk. FEBS Journal. 2011; 278:888-98. [PubMed: 21232019]

Plata-Salaman CR, Ilyin SE, Turrin NP, Gayle D, Flynn MC, Romanovitch AE, Kelly ME, Bureau Y, Anisman H, McIntyre DC. Kindling modulates the IL-1beta system, TNF-alpha, TGF-beta1, and neuropeptide mRNAs in specific brain regions. Brain Res. Mol. Brain Res. 2000; 75:248-58. [PubMed: 10686345]

Probert L, Akassoglou K, Pasparakis M, Kontogeorgos G, Kollias G. Spontaneous inflammatory demyelinating disease in transgenic mice showing central nervous system-specific expression of tumor necrosis factor alpha. Proc. Nat. Acad. Sci. 1995; 92:11294-8. [PubMed: 7479982]

Racine RJ. Modification of seizure activity by electrical stimulation. II. Motor seizure. Electroencephalogr. Clin. Neurophysiol. 1972; 32:281-94. [PubMed: 4110397]

Ravizza T, Gagliardi B, Noe F, Boer K, Aronica E, Vezzani A. Innate and adaptive immunity during epileptogenesis and spontaneous seizures: evidence from experimental models and human temporal lobe epilepsy. Neurobiol. Dis. 2008; 29:142-60. [PubMed: 17931873]

Riazi K, Galic MA, Kuzmiski JB, Ho W, Sharkey KA, Pittman QJ. Microglial activation and TNFalpha production mediate altered CNS excitability following peripheral inflammation. Proc. Nat. Acad. Sci. 2008; 105:17151-6. [PubMed: 18955701]

Seiffert E, Dreier JP, Ivens S, Bechmann I, Tomkins O, Heinemann U, Friedman A. Lasting bloodbrain barrier disruption induces epileptic focus in the rat somatosensory cortex. J. Neurosci. 2004; 24:7829-36. [PubMed: 15356194]

Shinoda S, Skradski SL, Araki T, Schindler CK, Meller R, Lan JQ, Taki W, Simon RP, Henshall DC. Formation of a tumour necrosis factor receptor 1 molecular scaffolding complex and activation of apoptosis signal-regulating kinase 1 during seizure-induced neuronal death. Eur. J. Neurosci. 2003; 17:2065-76. [PubMed: 12786973] 
van Vliet EA, da Costa Araujo S, Redeker S, van Schaik R, Aronica E, Gorter JA. Blood-brain barrier leakage may lead to progression of temporal lobe epilepsy. Brain. 2007; 130:521-34. [PubMed: 17124188]

Vezzani A, French J, Bartfai T, Baram TZ. The role of inflammation in epilepsy. Nat. Rev. Neurol. 2011; 7:31-40. [PubMed: 21135885]

Vezzani A, Friedman A, Dingledine RJ. The role of inflammation in epileptogenesis. Neuropharmacol. Apr 13.2012 EPub ahead of Print.

Wang DB, Dayton RD, Henning PP, Cain CD, Zhao LR, Schrott LM, Orchard EA, Knight DS, Klein RL. Expansive gene transfer in the rat CNS rapidly produces amyotrophic lateral sclerosis relevant sequelae when TDP-43 is overexpressed. Mol. Ther. 2010; 18:2064-74. [PubMed: 20877346]

Weinberg MS, Blake BL, Samulski RJ, McCown TJ. The influence of epileptic neuropathology and prior peripheral immunity on CNS transduction by rAAV2 and rAAV5. Gene Ther. 2011; 18:9618. [PubMed: 21490684]

Wright JL, Merchant RE. Blood-brain barrier changes following intracerebral injection of human recombinant tumor necrosis factor-alpha in the rat. J. Neuro-oncol. 1994; 20:17-25.

Wright JL, Merchant RE. Histopathological effects of intracerebral injections of human recombinant tumor necrosis factor-alpha in the rat. Acta neuropathol. 1992; 85:93-100. [PubMed: 1285500]

Wu Y, Wang X, Mo X, Xi Z, Xiao F, Li J, Zhu X, Luan G, Wang Y, Li Y, Zhang J. Expression of monocyte chemoattractant protein-1 in brain tissue of patients with intractable epilepsy. Clin. Neuropathol. 2008; 27:55-63. [PubMed: 18402383]

Yamamoto A, Schindler CK, Murphy BM, Bellver-Estelles C, So NK, Taki W, Meller R, Simon RP, Henshall DC. Evidence of tumor necrosis factor receptor 1 signaling in human temporal lobe epilepsy. Exp. Neurol. 2006; 202:410-20. [PubMed: 16919273] 


\section{Highlights}

- Limbic seizures increase type $1 \mathrm{TNF}$ receptors, but decrease type $2 \mathrm{TNF}$ receptors.

- TNF overexpression increases microglial activation and BBB compromise.

- Chronic activation of type $1 \mathrm{TNF}$ receptors increases seizure sensitivity.

- Chronic activation of type 2 TNF receptors decreases seizure sensitivity.

- Blockade of endogenous TNF significantly reduces seizure-induced cell death. 
A.
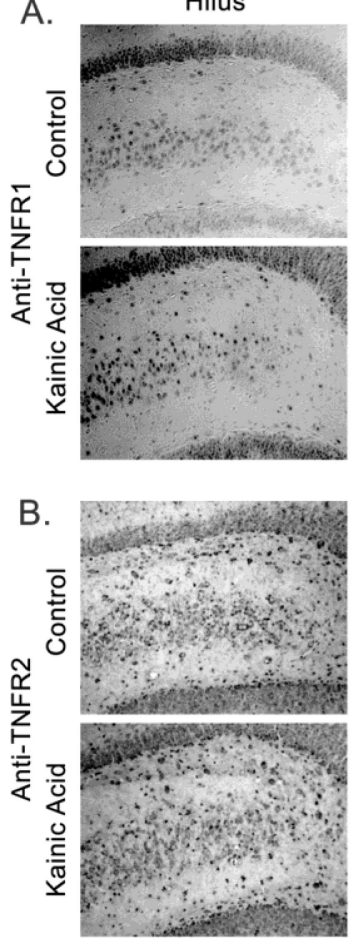

F.

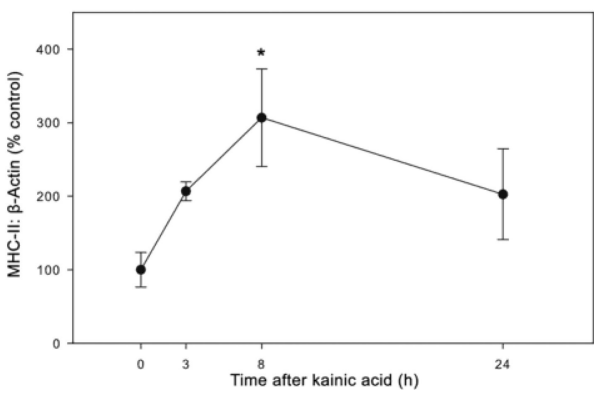

CA1
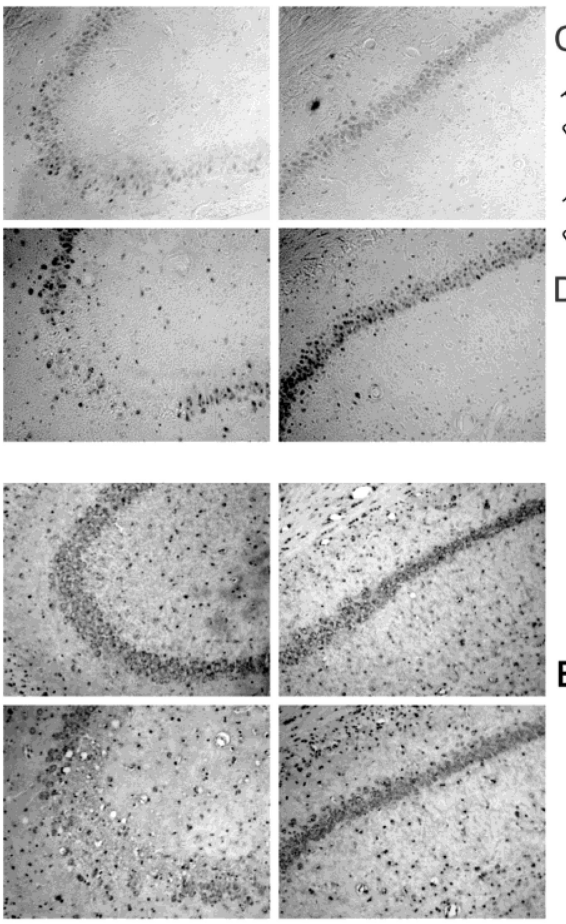

C. $\frac{\mathrm{Ctrl}}{-1 \mathrm{~h}} \frac{8 \mathrm{~h}}{24 \mathrm{~h}}$

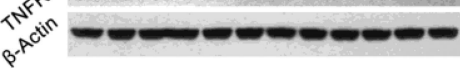

$2-0------\cdots$ $-0-0-000-0$

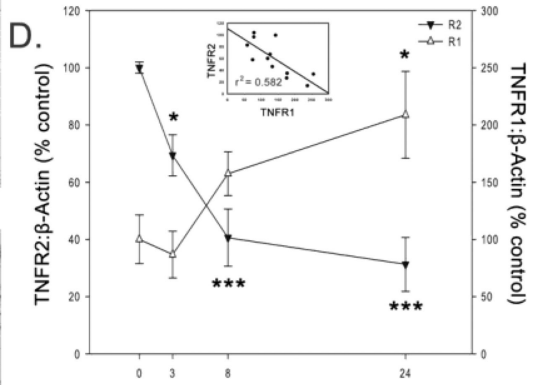

E.

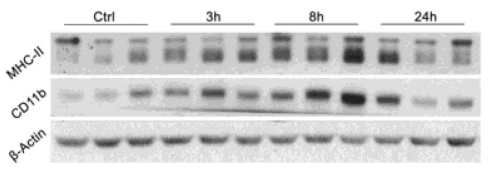

G

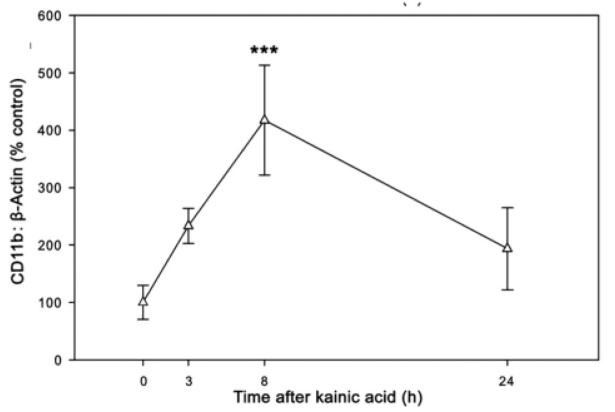

Figure 1. Seizures alter TNFR1 and TNFR2 protein expression and immune activation in the hippocampus

Panels A and B show immunostaining of TNFR1 and TNFR2, respectively, in the dorsal hippocampus in control and kainic-acid treated rats $24 \mathrm{~h}$ post-treatment. Panel $\mathrm{C}$ shows western blots probing TNFR1 and TNFR2 expression in whole hippocampus homogenates in rats at $0,3,8$, or $24 \mathrm{~h}$ post-kainic acid. $\beta$-actin expression was used to determine protein loading. Panel D shows average relative TNF-a receptor expression, based on densitometric analysis. The inset indicates a strong inverse correlation of TNFR1 protein expression to TNFR2 expression across all animals. Panel E shows western blots probing MHC-II and CD11-b expression in whole hippocampus homogenates in rats at $0,3,8$, or $24 \mathrm{~h}$ post-kainic acid. Panels F and G show average relative MHC-II and CD11-b expression, respectively, based on densitometric analysis. ***, *, Significantly different from untreated control group ( $\mathrm{P}<0.01,<0.05$, respectively). Error bars represent the standard error of the mean. 

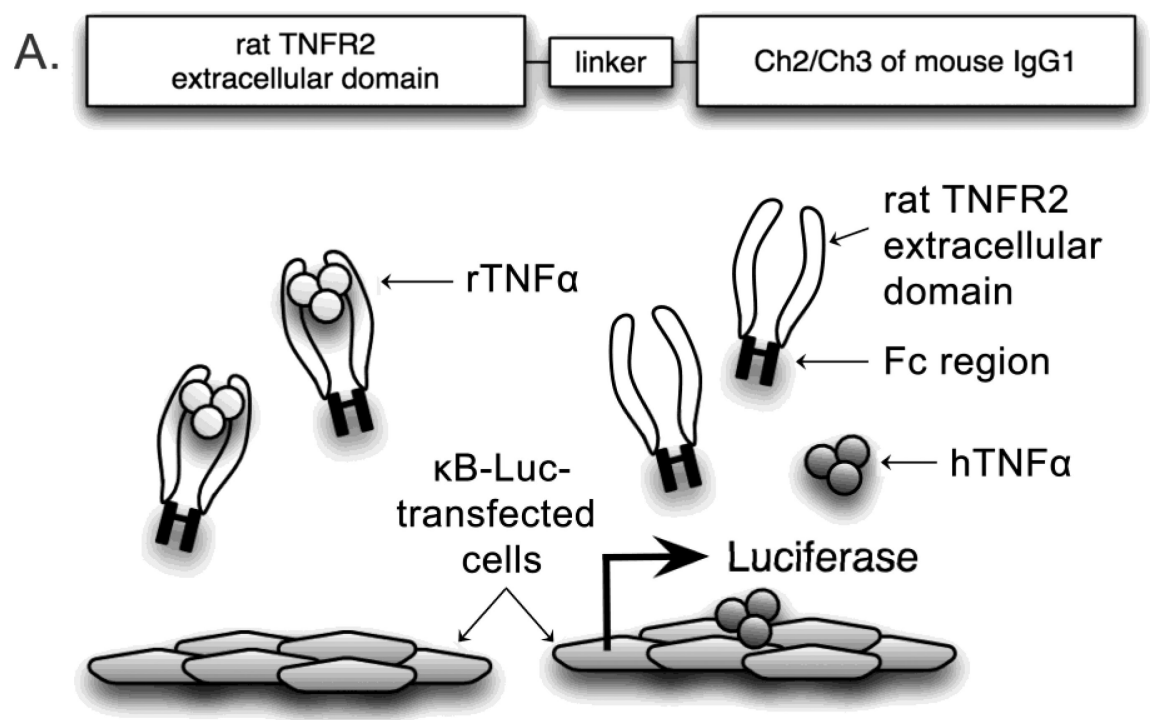

B.

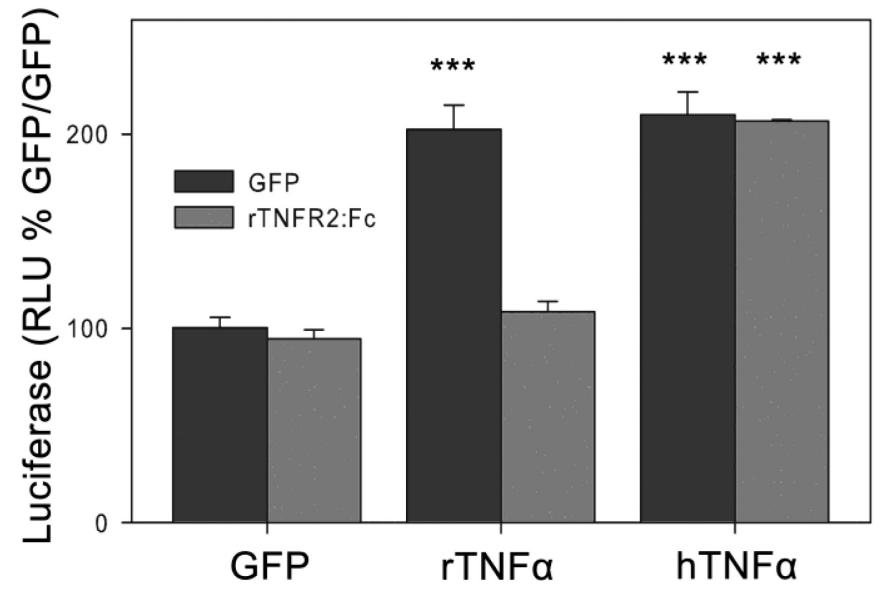

Figure 2. Rat TNFR2 is targeted by rat, but not human TNFa

Panel A, top: diagram of the chimeric rat TNFR2 extracellular domain linked to an IgG Fc domain. A linker peptide allows for flexibility of the receptor extracellular domain. Panel A, bottom left: Rat TNFR2:Fc binds to rat TNFa (rTNFa), preventing luciferase expression in кB-luciferase transfected HeLa cells. Panel A, bottom right: Rat TNFR2:Fc does not bind to human TNFa (hTNFa), which activates luciferase expression in $\mathrm{kB}$-luciferase transfected HeLa cells. Panel B shows relative light units read in HeLa cell lysates. GFP/GFP refers to the condition in which conditioned media from GFP transfected cells (control for rTNFa or hTNFa) was incubated with conditioned media from GFP transfected cells (control for TNFR2:Fc). ***, Significantly different from GFP/GFP group $(\mathrm{P}<0.01)$. Error bars represent the standard error of the mean. 
A.
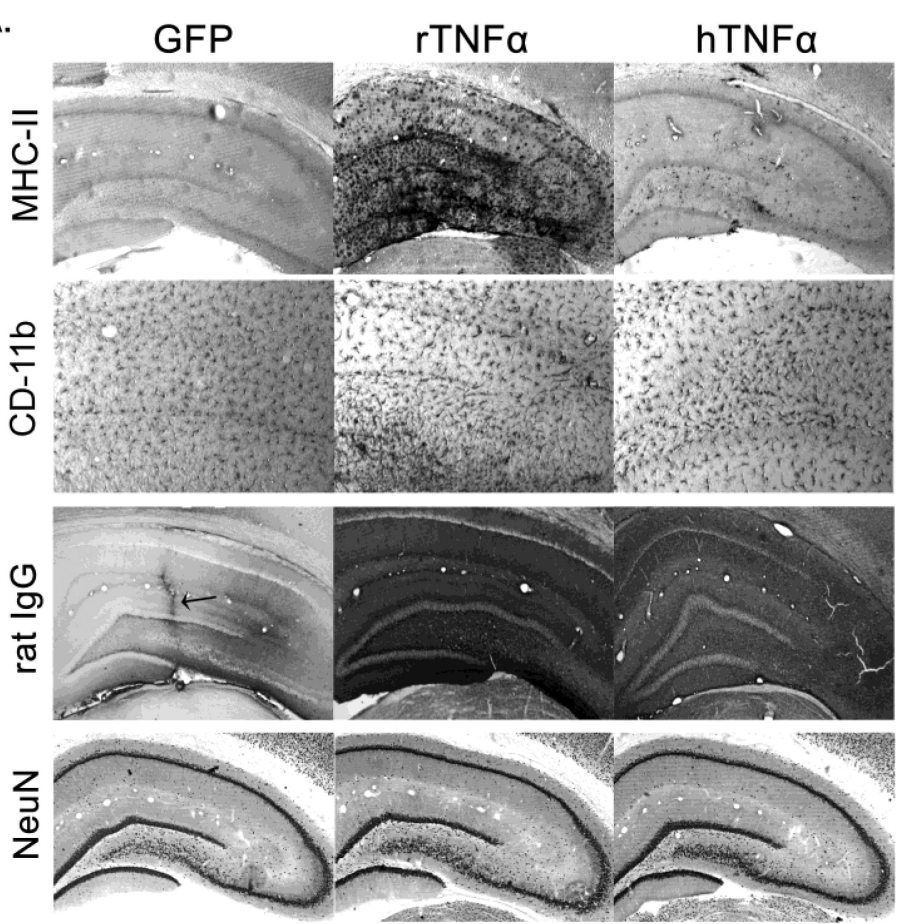

B.

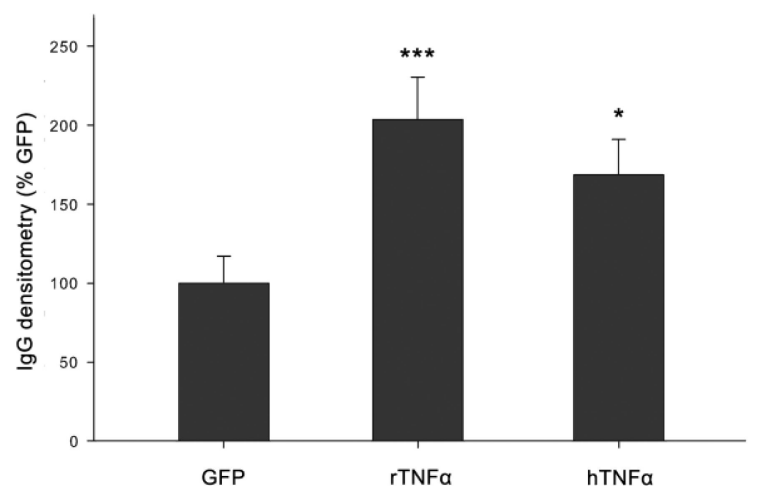

Figure 3. Effect of chronic TNFa expression on hippocampal inflammation, IgG extravasation and neuronal viability

Representative images show the dorsal hippocampi from AAV5-GFP, rTNFa, or hTNFatreated rats immunostained for MHC-II, CD11-b, IgG, or NeuN. There was very high MHCII expression in rTNFa-treated rats, throughout, but limited to, the hippocampus. There was much less relative MHC-II expression in the hippocampus of hTNFa-treated rats, but MHCII-positive cells still were present throughout the AAV-transduced area. No MHC-II-positive cells were found in GFP-treated rats. CD11b showed a similar pattern as MHC-II, but immunoreactivity was less robust. IgG extravasation was markedly elevated in both $\mathrm{TNFa}$ treated groups as compared to the GFP-treated control. An arrow indicates the needle tract seen in the GFP-treated animal which illustrates the relative lack of any injection effect alone on IgG extravasation. However, there was no evidence of cell death (NeuN). Panel B shows that IgG was significantly elevated in both the rTNF- $a$ and hTNF-a overexpressing groups versus the GFP controls. ***, *, Significantly different from untreated control group ( $\mathrm{P}<0.01,<0.05$, respectively). Error bars represent the standard error of the mean. 

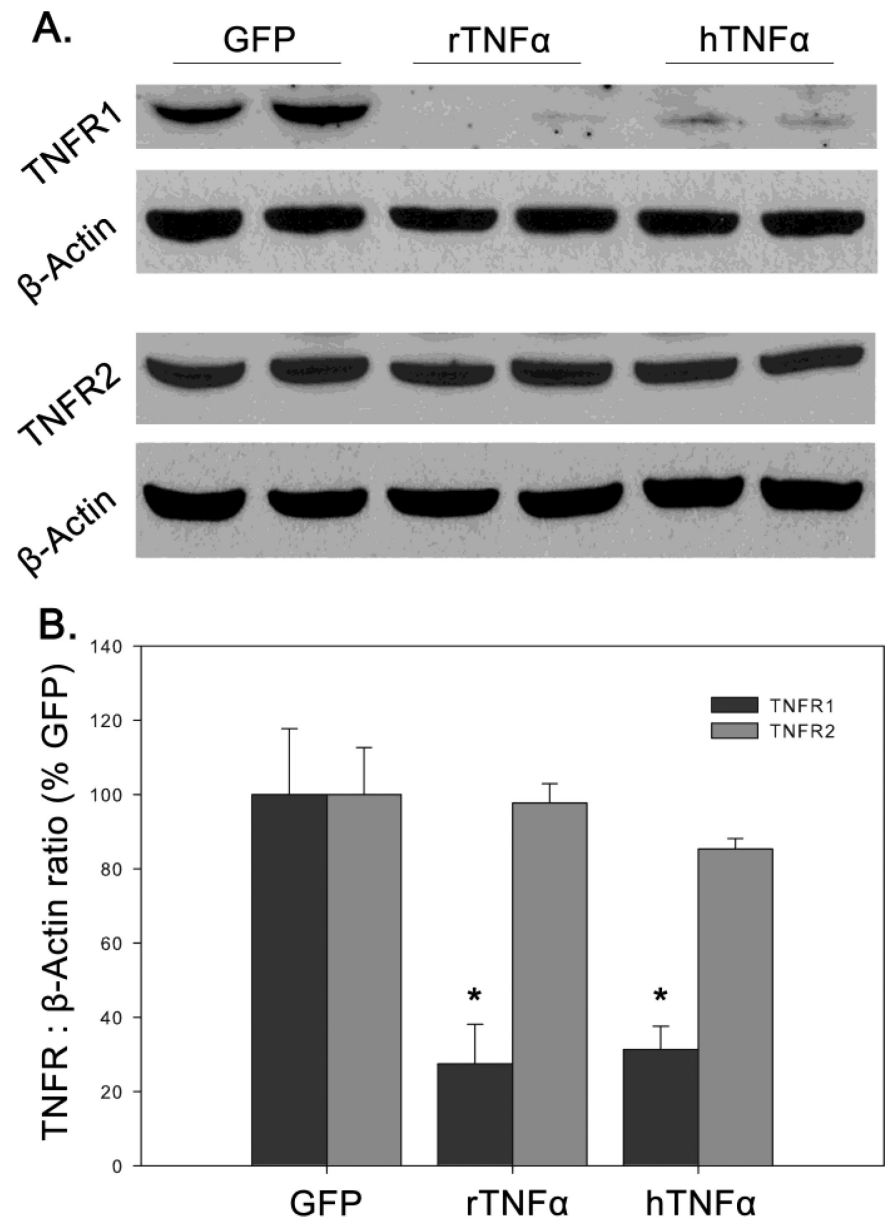

Figure 4. Effects of rat or human TNF-a expression on hippocampal TNFR1 and TNFR2 Panel A shows western blots probing TNFR1 and TNFR2 expression in whole hippocampus homogenates in rats 1 week post-AAV delivery. The AAV-based transgenes are listed as column heads. Panel B shows the densitometric analysis of western blot results, which clearly show a relative decrease of TNFR1 protein after chronic rTNFa or hTNFa expression, but no change in TNFR2 expression. ***, *, Significantly different $(\mathrm{P}<0.01,<$ 0.05 , respectively). Error bars represent the standard error of the mean. 

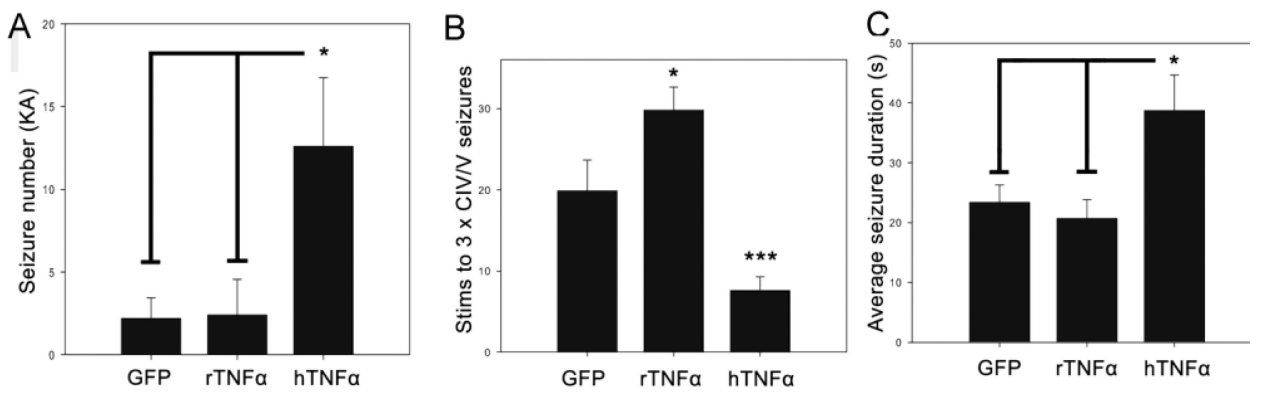

Figure 5. Effect of chronic TNFa expression on limbic seizures

Panel A shows that after amygdala delivery of kainic acid to AAV5-GFP, rTNF-a, or hTNF-a treated rats, hTNF-a treated rats exhibited significantly more class IV seizures than either GFP or rTNF- $a$ treated rats. Panel B shows that compared to GFP treated rats a greater number of stimulations was necessary to elicit three class IV seizures in rTNF-a treated rats, whereas fewer stimulations were necessary to elicit three class IV seizures in hTNFa-treated rats. Panel $\mathrm{C}$ shows that the average duration of class IV seizures in kindled rats was longer in hTNFa-treated rats. ***, *, Significantly different from GFP group. Error bars represent the standard error of the mean. 

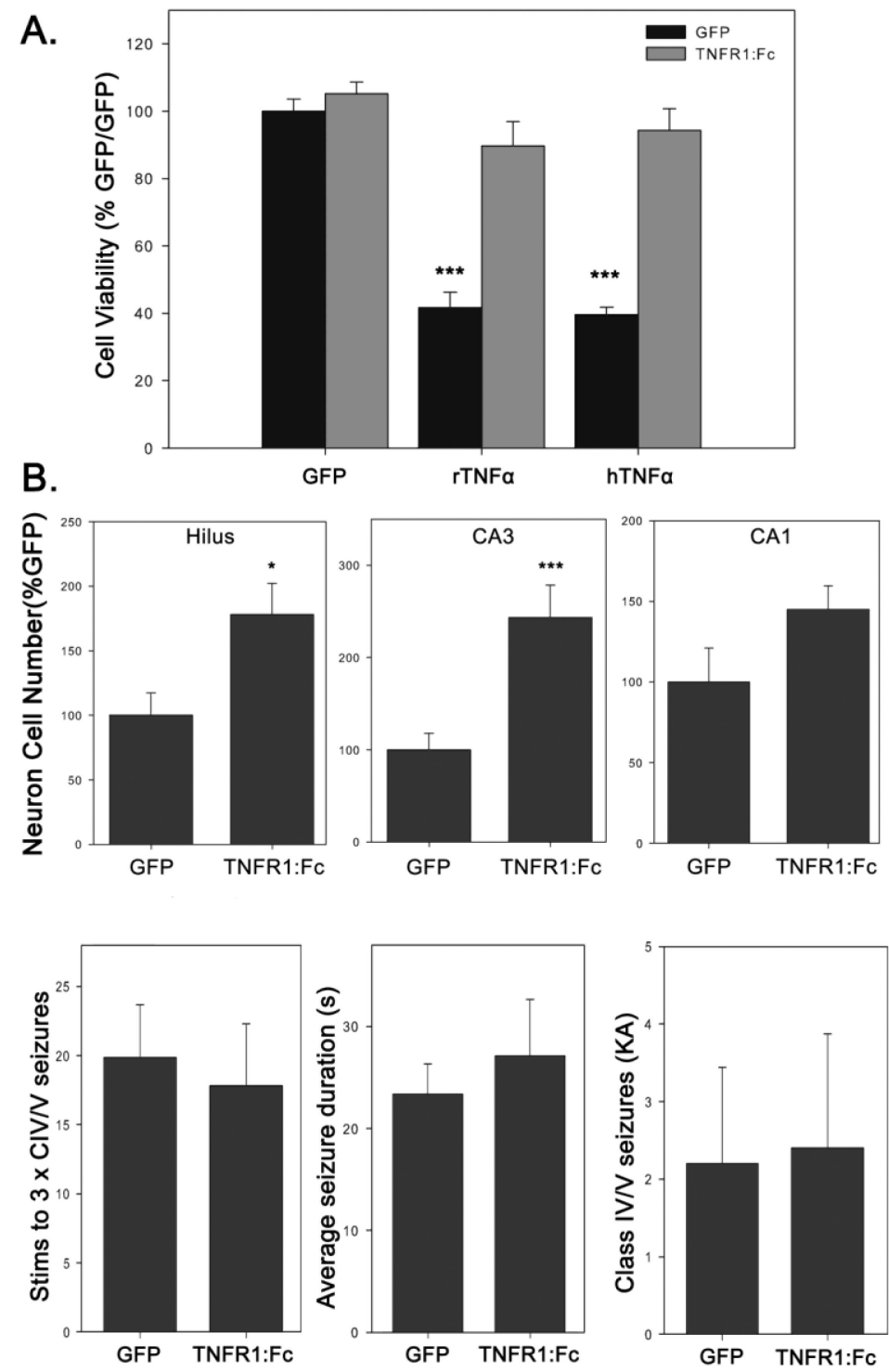

Figure 6. In vitro validation and in vivo effect of soluble decoy TNFR1:Fc expression on seizureinduced neuronal cell death and limbic seizures

Panel A shows that in vitro, TNFR1:Fc blocks the function of rat and human TNFa, preventing apoptosis in WEHI 164 clone 13 cells. ***, Significantly different from GFP/ GFP group ( $\mathrm{P}<0.01)$. Panel B shows that kainic acid-induced cell death is reduced in the hilus and CA3 in rats previously administered AAV5-TNFR1:Fc in the dorsal hippocampus as compared to AAV5-GFP- treated rats. Panel $\mathrm{C}$ shows that kainic acid-induced seizures, amygdala kindling, and average kindled seizure duration were similar in AAV5-TNFR1:Fctreated and -GFP-treated rats. ***, *, Significantly different from GFP control $(\mathrm{P}<0.01,<$ 0.05 , respectively). Error bars represent the standard error of the mean. 